\title{
Structure design of an innovative adaptive variable camber wing
}

\author{
An-Min Zhao ${ }^{1,3}$, Zou Hui ${ }^{1}$, De-Shan Liu ${ }^{1,3}$ and Bing-Fei Liu ${ }^{2}$ \\ ${ }^{1}$ School of Aeronautical Science and Engineering, Beihang University, Beijing, 100191, China \\ ${ }^{2}$ Airport college, Civil Aviation University of China, Tianjin, 300300, China \\ ${ }^{3}$ Beijing Dashan brothers Unmanned Aerial Vehicle Technology Company Limited, Beijing, 100191, China
}

\begin{abstract}
In this paper, an innovative double rib sheet structure is proposed, which can replace the traditional rigid hinge joint with the surface contact. On the one hand, the variable camber wing structural design not only can improve the capacity to sustain more load but also will not increase the overall weight of the wing. On the other hand, it is a simple mechanical structure design to achieve the total wing camber change. Then the numerical simulation results show that the maximum stress at the connect of the wing rib is $88.2 \mathrm{MPa}$, and the double ribs sheet engineering design meet the structural strength requirements. In addition, to make a fair comparison, the parameters of variable camber are fully referenced to the Talon Unmanned Aerial Vehicle (UAV). The results reveal that the total variable camber wing can further enhance aircraft flight efficiency by $29.4 \%$. The design of the whole variable camber wing structure proposed in this paper has high engineering value and feasibility.
\end{abstract}

\section{Introduction}

For low speed aircraft, the adaptive variable camber wing can effectively improve the lift and drag coefficients than conventional wing, delay the flow separation of the wing surface, and significantly improve the performance of the aircraft. Therefore, a lot of the adaptive variable wing research has been carried out at home and abroad.

In the 1980s, NASA and Boeing Launched the mission adaptive wing technology research, the abolition of the traditional aircraft control surface, the use of flexible composite material skin and the digital flight control system [1]. In 2003, in order to satisfy the needs of long flight time, the United States FlexSys Inc company designed a piezoelectric ceramic structure that used as a driver to alter the camber of wing [2]. In 2006, Kota et al proposed a flexible skin covering in the trailing edge of the wing and achieving the deformation of the entire wing by the smooth bending of the flexible trailing edge [3]. In 2009, Beihang University used shaped memory alloys as drive the trailing edge of the wing under temperature induction. The average lift of the wing was greater than $20 \%$ in the wind tunnel experimental [4]. In 2011, the University of Naples Federico in Italy adopting shape memory alloy (SMA) actuators designed with variable camber wing model [5]. At the same time, Abdullah, E. J adopted shape memory alloy (SMA) as the actuator in the adaptive airfoil control system. Results from the numerical simulation of the proposed controller are presented which demonstrate the potential of implementing SMA actuators in an adaptive airfoil control system for Unmanned Aerial Vehicle (UAV)[6].
In 2013, Liu weidong et al proposed a novel 0Poisson's ratio cosine honeycomb support structure of flexible skin, which can make the power consumption and driving force is lower [7]. In 2016, Li, Hongda design an innovative adaptive variable camber compliant wing, with skin that can change thickness and tailing edge morphing mechanism that is designed based on a new kind of artificial muscles. The results show that this method is capable of designing airfoils for this special wing in a quick and effective way [8].

From the design of the adaptive variable camber adaptive wing in domestic and abroad, it can be seen that in the realization of the adaptive deformation of the wing, from the traditional rigid structure to the compliant structure, from the conventional material to new functional material has certain research. But generally speaking, smart material drive cost is high, efficiency is low, it is difficult to realize engineering demand in present. While the traditional complex mechanical drive usually pays a greater price on the structural weight.

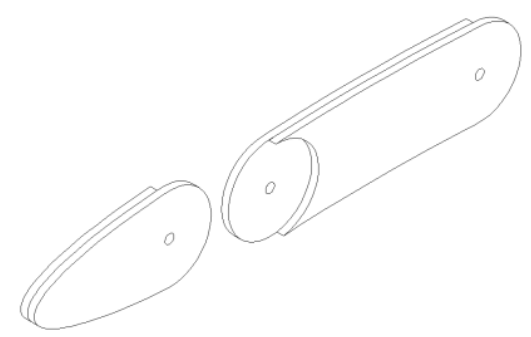

Figure 1. Double rib sheet structual model 
In this paper, a double rib sheet structure was designed in Fig. 1, which can achieve the overall wing variable camber. On the one hand, it is designed with a simple mechanical structure will not increase the weight of the wing weight, and the other side, the load transfer between the sections of the wing structures is converted from the point contact to surface contact, which leads to strong structural bearing capacity.

\section{Structural design of whole variable camber wing}

The Fig. 1 shows that the wing rib model are double rib sheet structure, one of which is a semicircular groove and the other layer is a circular ear piece which is in close contact. In this paper, the design of the compete wing rib is connected by four double ribs sheet, as shown in Fig. 2.

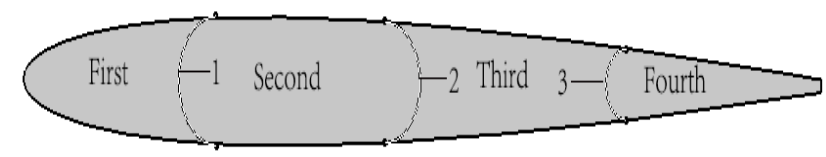

Figure 2. Four section wing rib structure models

The entire wing structure consists of four different wing structural sections in Fig. 3, which include the wing leading edge section, wing trailing edge section, wing mid-section and wing mid-aft section, which are connected to each other by a double wing rib sheet structure. The relative rotation between the ribs of the wing to achieve the overall variable camber wing.

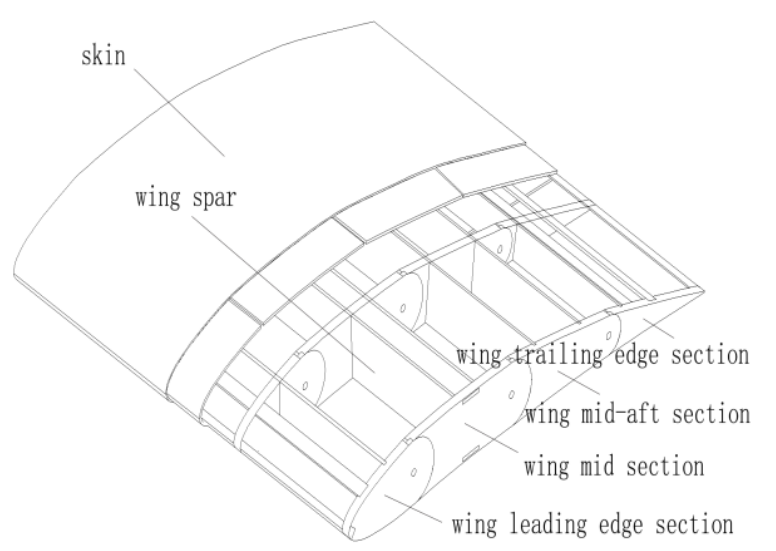

Figure 3. Variable camber wing structure model

The designed adaptive variable camber wing structure is same as that of the conventional wing, without any weight gain except the driving device.

\section{Engineering finite element analysis}

Whether the overall design of the strength of the variable camber wing structure can be qualified for large transport aircraft and civil aircraft. According to the technical parameters of the Lockheed C-130 "Hercules" transport aircraft (see Fig. 4) in Table 1 [9-12], the structural strength design of the whole variable ca4mber is carried out.

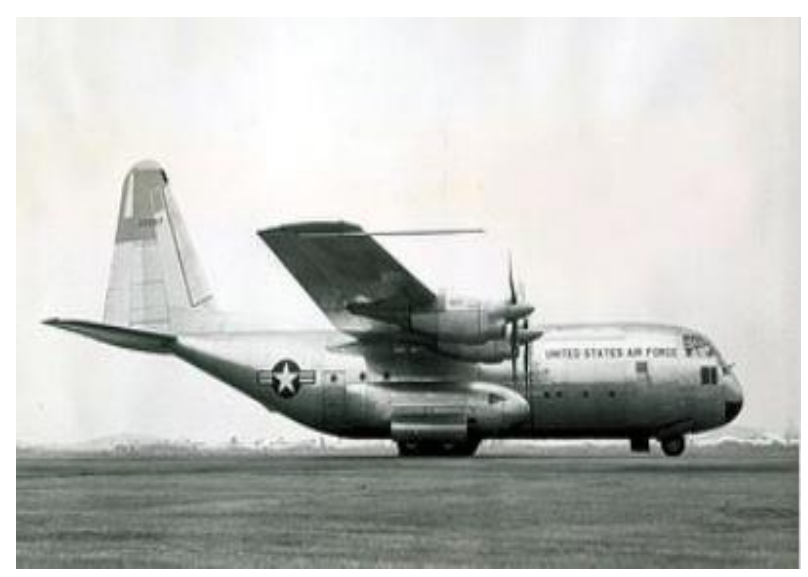

Figure 4. Lockheed C-130 Hercules transport plane

The analysis of the transmission of the aerodynamic load of the variable camber wing structure is simplified. The maximum bearing structure can be determined as the second wing rib structure section and the third wing rib section. Therefore, the area where the double ribs sheet is connected is considered to be a dangerous cross section. Based on the data Table 1 and the simplified results of the load, the aerodynamic force acting on the third segment can be calculated to be $339.4 \mathrm{~Pa}$.

It is assumed that the safety factor is 2 , the strength residual coefficient is 1.14 , the overload is $3 \mathrm{~g}$, and the design thickness of the fin is $15 \mathrm{~mm}$. Fig. 5 shows a finite model of the second section of the ribs completely fixed and the third section of the ribs in the loading direction with translational degree of freedom.

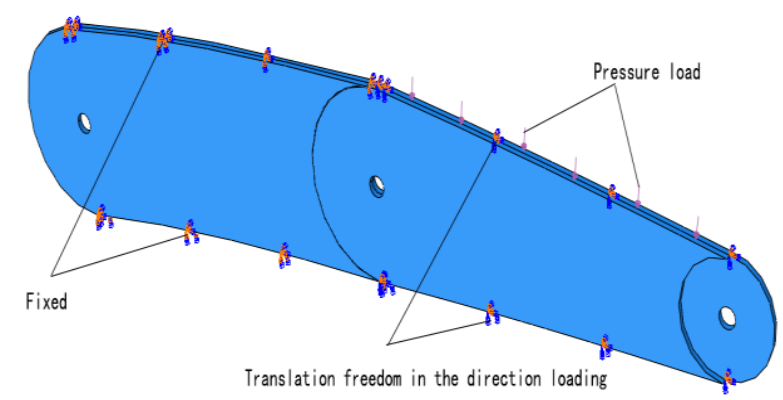

Figure 5. Boundary conditions and loads of finite element model

In this paper, the dynamic analysis method is adopted to complete the structural finite element analysis under the action of the surface pressure load. Fig. 6 shows that the maximum stress on the double rib sheet connection is 88.2 $\mathrm{MPa}$, which is much smaller than the yield stress of the material, as shown in Table 2. Therefore, the double rib sheet with a single thickness of $15 \mathrm{~mm}$ are safe to meet the actual carrying capacity. 


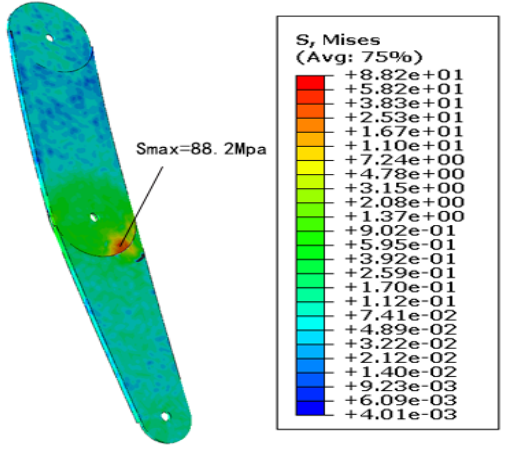

Figure 6. Stress contour of double rib sheet mode

\section{Flight experiment}

A flight test that Talon UAV and adaptive wing aircraft of the same design parameters were performed respectively is as follows. First, take a $5000 \mathrm{mAh} 4 \mathrm{~S}$ model battery, which has a full voltage of $16.4 \mathrm{~V}$ to the variable camber wing aircraft power. In the adaptive flight state of the wing, respectively, each flight of $12 \mathrm{~m} / \mathrm{s}$, $14 \mathrm{~m} / \mathrm{s}, 16 \mathrm{~m} / \mathrm{s}$ for 5 minutes, the voltage drop of the battery was $1.2 \mathrm{~V}$. Then, we adopted the same battery in the case of full voltage for Talon UAV to compete the same flight mission, measured the voltage drop of battery was $1.7 \mathrm{~V}$. The specific flight data is shown in Table 3.

As shown in Table 3, the variable camber wing in adaptive flight state is $0.5 \mathrm{~V}$ lower than that of the Talon UAV. That is, the variable camber adaptive flight than the same parameters Talon UAV flight efficiency increase by $29.4 \%$.

\section{Conclusions}

In this paper, an innovation double rib sheet structure is studied that allows the overall structure of the wing to change according to the relative rotation the double rib sheet joint. This comparison study indicates that this adaptive variable camber wing has better aerodynamic performance than the tradition wing. Main conclusions for the innovation double rib sheet research of this paper are as follows:

1. An innovative double rib sheet structure is designed, which achieves the whole variable camber of wing with a simple mechanical structure, and does not increase the overall structural weight of the wing.

2. The load transfer mode of the new designed of variable camber wing structure is surface contact, which makes the structure more loading-bearing.

3. Taking the Lockheed C-130 Hercules transport aircraft as the engineering prototype, its aircraft variable camber wing designed with double rib sheet structure. Based on the numerical simulation results show that the maximum stress at the connect of the wing rib is $88.2 \mathrm{MPa}$, and the double ribs sheet design satisfies the structural strength requirements.

4. This paper proposes a new design method which can realize the overall variable camber of wing. Compared with the design scheme of traditional fixed wing Talon UAV, the total variable camber wing can further enhance aircraft flight efficiency by $29.4 \%$.

Table 1. The technical parameters of Lockheed C-130 Hercules transport plane.

\begin{tabular}{|c|c|c|c|c|}
\hline Span $(\mathrm{m})$ & $\begin{array}{c}\text { Wing } \\
\text { area }\left(\mathrm{m}^{2}\right)\end{array}$ & $\begin{array}{c}\text { Maximum take-off } \\
\text { weight }(\mathrm{kg})\end{array}$ & Maximum flight speed $(\mathrm{km} / \mathrm{h})$ & Wing load $\left(\mathrm{kg} / \mathrm{m}^{2}\right)$ \\
\hline 40.4 & 162 & 70300 & 592 & 434 \\
\hline
\end{tabular}

Table 2. Material property of double rib sheet.

\begin{tabular}{|c|c|c|c|}
\hline$\rho\left(\mathrm{kg} / \mathrm{m}^{3}\right)$ & $E\left(\mathrm{~N} / \mathrm{m}^{2}\right)$ & $\sigma\left(\mathrm{N} / \mathrm{m}^{2}\right)$ & $v$ \\
\hline 40.4 & 162 & 70300 & 592 \\
\hline
\end{tabular}

Table 3. Comparison of flight test of adaptive camber aircraft and Talon aircraft.

\begin{tabular}{|c|c|c|c|c|}
\hline Test & Aircraft type & Cruise setting & Voltage drop & Dissipative energy \\
\hline Test I & Adaptive variable camber wing & $\begin{array}{l}5 \mathrm{~min} 12 \mathrm{~m} / \mathrm{s} \\
5 \mathrm{~min} 14 \mathrm{~m} / \mathrm{s} \\
5 \mathrm{~min} 16 \mathrm{~m} / \mathrm{s}\end{array}$ & $1.2 \mathrm{~V}$ & $21600 \mathrm{~J}$ \\
\hline Test II & Talon & $\begin{array}{l}5 \mathrm{~min} 12 \mathrm{~m} / \mathrm{s} \\
5 \mathrm{~min} 14 \mathrm{~m} / \mathrm{s} \\
5 \mathrm{~min} 16 \mathrm{~m} / \mathrm{s}\end{array}$ & $1.7 \mathrm{~V}$ & $30600 \mathrm{~J}$ \\
\hline
\end{tabular}




\section{Acknowledgement}

The authors gratefully acknowledge the financial support of National Natural Science Foundation of China (No. 11502284) and it is also supported by "the Fundamental Research Funds for the Central Universities (3122016C006)" of China.

\section{Reference}

1. POWERS S, WEBB L, FRIEND E, LOKOS W, editors. Flight test results from a supercritical mission adaptive wing with smooth variable camber. 28th National Heat Transfer Conference; 1992.

2. Zhu H, Liu WD, Zhao CS. Morphing Aircraft and Its Morph-driving Techniques[J]. Machine Building \& Automation. 2010.

3. Kota S, Osborn R, Ervin G, Maric D, Flick P, Paul D. Mission Adaptive Compliant Wing - Design , Fabrication and Flight Test Mission Adaptive Compliant Wing[J]. 2006.

4. Li Jun, Qin YanHua, et, al Development of a morphing wing with adaptive capability[J]. Acta Aerodynamica Sinica. 2009,27(5):505-8.

5. Barbarino S, Pecora R, Lecce L, Concilio A, Ameduri S, De Rosa L. Airfoil Structural Morphing Based on SMA Actuator Series: Numerical and Experimental Studies[J]. J Intell Mater Syst Struct. 2011,22(10):987-1004.

6. Abdullah, E.J., C. Bil, and S. Watkins, Adaptive airfoil control system using shape memory alloy actuator for unmanned aerial vehicle. Incorporating
Sustainable Practice in Mechanics of Structures and Materials, ed. S. Fragomeni, et al. 2011, Boca Raton: Crc Press-Taylor \& Francis Group. 141-146.

7. LiuWeidong, ZhuHua, ZhouShengqiang, BaiYalei, WangYuan, ZhaoChunsheng. Inplanecorrugatedcosinehoneycombfor1Dmorphingski nanditsapplicationonvariablecamberwing $[\mathrm{J}]$. Chinese Journal of Aeronautic. 2013,26(4):935-42.

8. Li HD, Ang HS. Preliminary airfoil design of an innovative adaptive variable camber compliant wing[J]. J Vibroeng. 2016,18(3):1861-73.

9. Spicer CW, Holdren MW, Cowen KA, Joseph DW, Satola J, Goodwin B, et al. Rapid measurement of emissions from military aircraft turbine engines by downstream extractive sampling of aircraft on the ground: Results for C-130 and F-15 aircraft[J]. Atmos Environ. 2009,43(16):2612-22.

10. Haywood J, Francis P, Osborne S, et al. Radiative properties and direct radiative effect of Saharan dust measured by the C-130 aircraft during SHADE: 1 . Solar spectrum. 2003; 108: 8577.

11. Haywood JM, Osborne SR, Francis PN, et al. The mean physical and optical properties of regional haze dominated by biomass burning aerosol measured from the C-130 aircraft during SAFARI 2000. Journal of Geophysical Research Atmospheres. 2003; 108: 225-31.

12. Highwood EJ, Haywood JM, Silverstone MD, Newman SM, Taylor JP. Radiative properties and direct effect of Saharan dust measured by the C-130 aircraft during Saharan Dust Experiment (SHADE): 2. Terrestrial spectrum. Journal of Geophysical Research Atmospheres. 2003; 108: SAH 5-1. 